\title{
Calculating the load on the room cooling ceiling panel at convective heat gains
}

\author{
Elena Malyavina ${ }^{1 *}$ and Alexander Lomakin $^{1}$ \\ ${ }^{1}$ Moscow State University of Civil Engineering, Yaroslavskoye sh., 26, Moscow, 129337, Russia
}

\begin{abstract}
A well-known statement of the theory of thermal stability asserts that when a harmonically time-changing convective heat flux enters a room, it can only be assimilated by a radiant cooling system if the assimilating flow exceeds the perturbing convective flow in magnitude. However, in engineering practice, there are no purely radiant systems. Therefore, the article has considered a ceiling cooling panel as a room cooling system, the heat flow from which is of a radiant-convective nature. The convective heat access to the room is constant during the working hours from 9 a.m. to 6 p.m. The task of determining the load on the cooling system has been performed by calculations.. Herewith, the rooms of different internal thermal stability have been considered. According to the calculation results, it has been found that, since the amount of the heat gains remains constant for a long period of time, the process of the room cooling comes almost to a stationary state and does not depend on the room thermal stability with assimilated heat gains, the value of which in different options varied from $100 \mathrm{~W}$ to $1000 \mathrm{~W}$. It has been found, that when the temperature difference between the panel surface and the surrounding surfaces increases, the proportion of the convective assimilating flow becomes bigger.
\end{abstract}

\section{Introduction}

Calculating the load on room cooling systems is an important task for a design engineer [17]. It is known that the room thermal stability can play a significant role here.

In [8] the provisions of the theory of heat stability $[9,10,11]$ are considered with respect to the values of the stabilizing convective flow for smoothing the harmonically changing radiant flux. It is shown that the assimilating convective flow will be less if the heat absorption index of the room is bigger. At the same time, according to the theory of heat stability, the value of the required radiant heat fluxes, which change over time and assimilate convective heat gains, will be the greater the greater the heat stability $[10,11]$.

The $a_{\mathrm{r}}$ coefficient shows how many times the load that changes harmonically over time is greater than the harmonic perturbing flow:

*Corresponding author: emal@list.ru 


$$
1+Y_{r} / \sum_{i=1}^{I}\left(\alpha_{\kappa, i} \cdot A_{i}\right)
$$

where $\mathrm{Y}_{\mathrm{r}}$ is the room heat absorption, $\mathrm{W} /{ }^{\circ} \mathrm{C}$;

$\alpha_{\mathrm{K}}$ - the coefficient of convective heat transfer for each surface facing the room, $\mathrm{W} /\left(\mathrm{m}^{2}\right.$ $\left.{ }^{\circ} \mathrm{C}\right)$;

$i$ - the sequence number of the inner surface of the enclosing structure;

$I$ - the number of surfaces of internal enclosing structures facing the room;

$A_{i}$ - the area of the $i^{\text {th }}$ inner surface of the enclosing structure, $\mathrm{m}^{2}$.

Unfortunately, it is not possible to verify this statement in its pure form, since there are no ways to cool a room with a purely radiant source. In addition, convective heat gains usually change not according to the harmonic law, and are almost constant during the working hours.

The purpose of this article is to estimate the effect of the room internal thermal stability on the cooling load from the convective heat gains during the working hours from 9 a.m. to 6 p.m. The ceiling panel acts as a room's cooling system.

\section{Method of calculations}

The assessment of the influence of the room internal thermal stability on the cooling load formation has been performed by calculation. When modeling the daily non-stationary thermal mode of the room, the calculation of non-stationary heat transfer through all both external and internal enclosing structures has been made by the method of finite differences in Cartesian coordinates using an implicit scheme. Provision has been made of solution of the complete system of radiant heat exchange equations of all surfaces facing the room between them, as well as the convective heat exchange of each surface with the room air $[12,13]$. When considering radiant heat exchange, the irradiation coefficients of the surrounding surfaces were calculated for each surface, and the sum of these coefficients for each surface was strictly equal to 1.000 .

Since the numerical method of finite differences does not allow to generalize the thermo-physical characteristics of premises to assess their internal thermal stability, this work has used the characteristic which is adopted in the theory of heat stability $[12,14,15]$ - the index of the room heat absorption. This is all the more legitimate because the periodic task is being solved.

Provision has been made of three ordinary rooms on the building intermediate floors of the same geometry: $4.5 \mathrm{~m} \mathrm{x} 4.5 \mathrm{~m}$ in plan and $3.5 \mathrm{~m}$ in height. The rooms had different internal thermal resistance mainly due to different interior finishes:

- of high thermal stability i.e. the walls and partitions made of reinforced concrete, the ceiling is a reinforced concrete slab, the floor is a gypsum slab over a reinforced concrete slab;

- of medium thermal stability i.e. the walls and the partitions have been calculated taking into account a sand-cement plaster, the ceiling is a concrete slab, the floor is covered by linoleum over a concrete slab;

- of low thermal stability i.e. .e. the walls and the partitions have been calculated taking into account the perlite plaster, the ceiling is a reinforced concrete slab, the floor is a carpet over a reinforced concrete slab.

In order to exclude any heat fluxes that penetrate the room, except for the studied ones, a room without external enclosing structures has been provided. The absence of whatever heat flux has been set on the thermal axis of each room enclosing structure. For the room of a high thermal stability $Y_{\text {пा }}$ has been taken equal to $1727 \mathrm{~W} /{ }^{\circ} \mathrm{C}$, for the room of a medium 
thermal stability $Y_{\text {п }}=1099 \mathrm{~W} /{ }^{\circ} \mathrm{C}$, for the room of a low thermal stability $Y_{\text {п }}=430 \mathrm{~W} /{ }^{\circ} \mathrm{C}$.

In order to maintain a constant resulting room temperature the changing heat and cold flows of the same nature must be equal at each time. If it is not possible to track the heat access changes in the time, the assimilating flows become different from them, and the process includes the thermal stability of the room enclosing structures.

In the ceiling cooling panel, cold water begins to circulate 30 minutes before the working day and throughout the working hours. The temperature of the coolant circulating in the ceiling panel is selected so that the resulting room temperature (the average between the air temperature and the radiation temperature of the room) does not deviate from $24{ }^{\circ} \mathrm{C}$ by more than $0.2^{\circ} \mathrm{C}$ in any direction.

\section{Calculation results and their analysis}

In Table 1 some calculation results are given, which, first, can be used to judge the accuracy of the calculation. It is clear that within the daily cycle, the amount of heat gains and the amount of the cooling flows must be equal to each other. A comparison of daily heat gains and daily amounts of cooling flows shows that the differences are no more than $1 \%$. Secondly, the data in the Table 1 show that almost all heat gains are assimilated during working hours, and an additional cooling of the room after the working day is of no practical importance.

Table 1. Amounts of heat and cooling flows per 24 hours and per working hours

\begin{tabular}{|l|l|l|l|l|l|}
\hline $\begin{array}{l}\text { Room } \\
\text { internal } \\
\text { thermal } \\
\text { stability }\end{array}$ & $\begin{array}{l}\text { 24-hour } \\
\text { amount of } \\
\text { convectiv } \\
\text { e heat } \\
\text { gains, } \\
\mathrm{W} \cdot \mathrm{h}\end{array}$ & $\begin{array}{l}\text { 24-hour } \\
\text { amount of } \\
\text { radiant } \\
\text { cooling load, } \\
\mathrm{W} \cdot \mathrm{h}\end{array}$ & $\begin{array}{l}\text { 24-hour } \\
\text { amount of } \\
\text { convective } \\
\text { cooling } \\
\text { load, W·h }\end{array}$ & $\begin{array}{l}\text { Amount of } \\
\text { radiant } \\
\text { cooling load } \\
\text { in working } \\
\text { hours, } \\
\mathrm{W} \cdot \mathrm{h}\end{array}$ & $\begin{array}{l}\text { Amount of } \\
\text { convective } \\
\text { cooling load } \\
\text { in working } \\
\text { hours, } \\
\mathrm{W} \cdot \mathrm{h}\end{array}$ \\
\hline \multirow{4}{*}{ low } & 900 & 424.6 & 474.5 & 433.6 & 472.9 \\
\cline { 2 - 7 } & 4500 & 1780.6 & 2718.3 & 1791.0 & 2718.3 \\
\cline { 2 - 7 } & 9000 & 3254.8 & 5743.7 & 3252.4 & 5717.6 \\
\hline \multirow{3}{*}{ medium } & 900 & 428.1 & 476.2 & 437.6 & 474.8 \\
\cline { 2 - 7 } & 4500 & 1784.5 & 2719.6 & 1796.2 & 2709.2 \\
\hline \multirow{3}{*}{ high } & 9000 & 3258.5 & 5745.3 & 3260.7 & 5720.3 \\
\cline { 2 - 7 } & 900 & 419.8 & 471.4 & 429.6 & 470.0 \\
\cline { 2 - 7 } & 4500 & 1777.8 & 2713.3 & 1789.5 & 2703.0 \\
\hline
\end{tabular}

It may be interesting, that the panel cools the room due to the radiant heat exchange of its surface with all other surfaces facing the room, and due to the convective heat exchange with the room air. Moreover, in the total daily load the ratio of the radiant flow shares to the convective load ones varies from $47.2 \%$ to $52.8 \%$ for heat gains equal to $100 \mathrm{~W}$, to $36.2 \%$ to $63.8 \%$ for heat gains equal to $1000 \mathrm{~W}$. These ratios do not depend on the thermal stability.

The increase in the cold convective fraction in the assimilating flow with an increase in the heat flux can be explained by an inevitable increase in the difference between the surface temperature of the cooling panel and the average temperature of the surrounding surfaces.

Thus, with constant convective heat access to the room during the working hours, the 
temperature changes of the panel and all surfaces facing the room is relatively quickly stabilized, regardless of the room thermal stability.

The same result has been confirmed by the Table 2, which provides data on the maximum heat fluxes during the working hours. It can be seen that the divergences of convective heat supply fluxes and the cooling load flows that assimilate them are within the calculation accuracy.

Table 2. Maximum heat gain of the room and maximum load on the cooling system

\begin{tabular}{|c|c|c|c|c|c|c|}
\hline \multirow{2}{*}{$\begin{array}{c}\text { Room } \\
\text { internal } \\
\text { thermal } \\
\text { stability }\end{array}$} & \multicolumn{2}{|c|}{ Maximum heat gains } & \multicolumn{4}{|c|}{ Maximum cooling load } \\
\cline { 2 - 7 } & Total, W & Hours, $\mathrm{h}$ & $\begin{array}{c}\text { Total, } \\
\mathrm{W}\end{array}$ & $\begin{array}{c}\text { Radiant, } \\
\mathrm{W}\end{array}$ & $\begin{array}{c}\text { Convective, } \\
\mathrm{W}\end{array}$ & $\begin{array}{c}\text { Time, } \\
\mathrm{h}\end{array}$ \\
\hline low & 100 & $9-18$ & 99.7 & 46.8 & 52.9 & $18-00$ \\
\hline & 500 & $9-18$ & 494.5 & 193.7 & 300.8 & $18-00$ \\
\hline & 1000 & $9-18$ & 1005.1 & 359.7 & 645.4 & $17-30$ \\
\hline medium & 100 & $9-18$ & 99.8 & 46.9 & 52.9 & $18-00$ \\
\hline & 500 & $9-18$ & 503.2 & 198.2 & 305.0 & $15-45$ \\
\hline & 1000 & $9-18$ & 996.8 & 356.2 & 640.6 & $18-00$ \\
\hline high & 100 & $9-18$ & 98.2 & 45.9 & 52.3 & $18-00$ \\
\hline & 500 & $9-18$ & 501.6 & 197.4 & 304.2 & $15-45$ \\
\hline & 1000 & $9-18$ & 994.5 & 355.1 & 639.4 & $18-00$ \\
\hline
\end{tabular}

The Fig. 1 show the changes in the air temperature and the resultant of the room, as well as the temperature of some surfaces facing the room at convective heat inputs of $100 \mathrm{~W}$ and $1000 \mathrm{~W}$. The presented drawing refer to a room with a high thermal stability. However, the temperature changes in the rooms with medium and low thermal stabilities differ slightly (by $0.1-0.2^{0} \mathrm{C}$ ) from those presented, and only when the panel becomes cooled after it has been switched on and heated after it has been turned off. The comparison of the figures makes it evident, that the difference between the resulting room temperature and the internal air temperature is determined by the value of convective heat gains. 

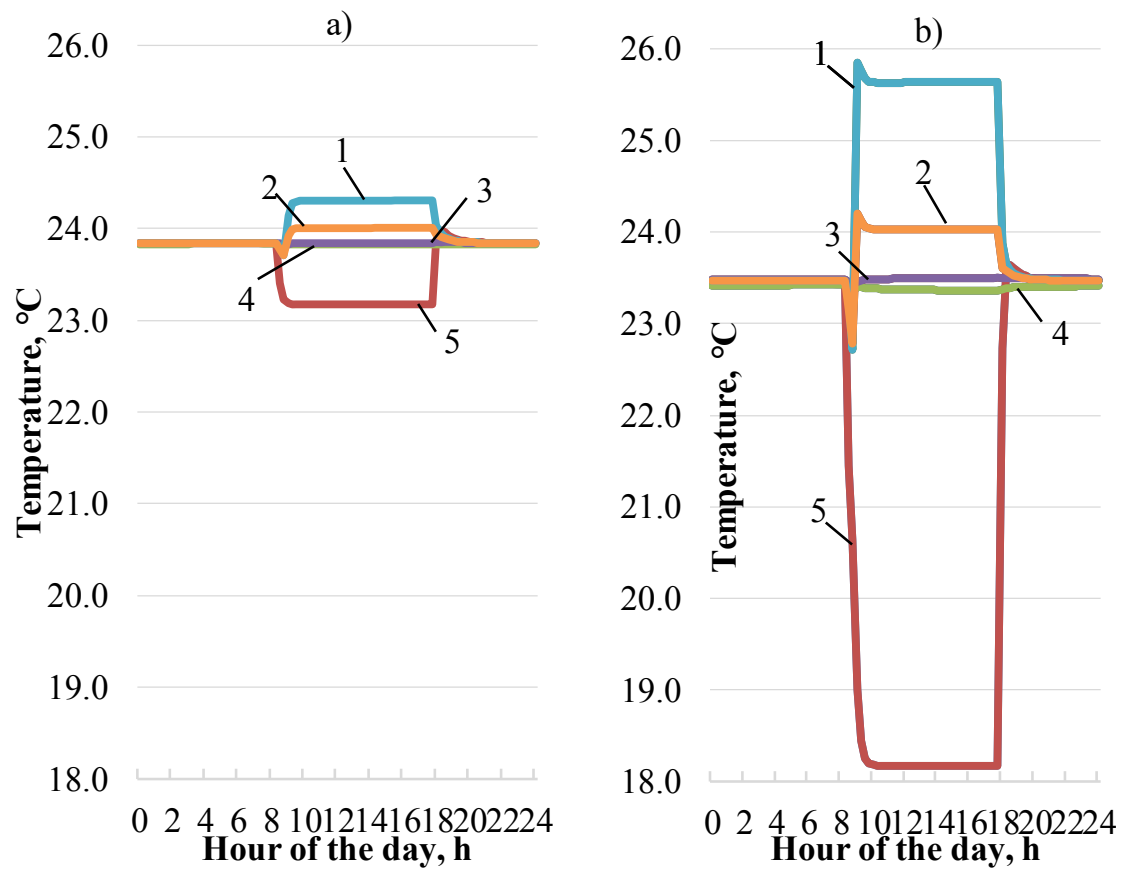

Fig. 1. Daily temperature changes in a room with a high thermal stability a) when $100 \mathrm{~W}$ of the convective heat are received; b) when $1000 \mathrm{~W}$ of the convective heat are received: 1 - air, 2 resultant, 3-partition surface, 4-floor surface, 5-cooling ceiling surface.

The calculation results showed that when a convective heat flux of different power from $100 \mathrm{~W}$ to $1000 \mathrm{~W}$ is supplied to the room, its assimilation by the cooling ceiling panel occurs almost at a constant intensity during the working hours. The assimilating flow increases slightly (within $1 \mathrm{~W}$ ) after an hour of initial cooling of the panel itself and until the end of the working day. Moreover, the panel cooling time does not depend much both on the disturbing flow rate, and on the thermal stability of the room. This is because the temperature of the coolant has been selected so that the required resulting room temperature with the above accuracy could be maintained from the beginning of the working day (i.e. from 9 a.m.). Therefore, the thermal stability of the room manifests itself only in the rate of the panel heating after the cooling medium circulation ceases. However, the room cooling thermal flow is so small that it has no practical value.

\section{Conclusion}

Usually, the cooling load on the cooling system in the design practice is determined by the maximum amount of heat gains in the room during the working hours of the design 24 hours $[4,5]$. The performed study showed that the sum of radiant and convective cooling flows from the ceiling panel, which assimilate convective heat gains, is almost equal to the value of heat gains.

\section{References}

1. B. Slee, T. Parkinson, R. Hyde, Cut. E. in Arch. Sc., 325-333 (2013). 
2. L. Evangelisti et al., Sust., 7, 4514-4524 (2014).

3. C. Kendrick et al., En. and build., 48, 40-49 (2012).

4. C. Ellerbrok, En. Pr., 46, 214-219 (2014).

5. S. A. Al-Sanea, M. F. Zedan, S. N. Al-Hussain, App. En., 89, 430-442 (2012).

6. L. S. Wang et al., En. and Build., 78, 79-88 (2014).

7. X. Kong, S. Lu, Y. Li, J. Huang, S. Liu., En. and Build., 81, 404-415 (2014). DOI: 10.1016/j.enbuild.2014.06.044

8. G.P. Vasilyev, V.F. Gornov, P.I. Konstantinov, M.V. Kolesova., I.A. Korneva. Mag. of Civ. Eng., 4, 62-72 (2017). DOI: 10.18720/MCE.72.8. 13.

9. A. E. Zakharevich Nauka I tekhn., 6, 476-480 (2016). DOI: 10.21122/2227-1031 2016-15-6-476-480.

10. T.A. Rafalskaya, R.Sh. Mansurov, A.O. Raginskaya, D.A. Rasenko. Izv. Vuz. Inv. Stroit.. Nedv. 7/ 4, 192-203 (2017) DOI: 10.21285/2227-2917-4-192-203

11. T. A. Datciuk., E.A. Anshukova, Bul. of Civ. Eng. [Vest. Grazhd. inzh.], 5, 160-165 (2019). DOI 10.23968/1999-5571-2019-16-5-160-165

12. O.D. Samarin, Mag. of Civ. Eng., 78, 161-168 (2018) DOI: 10.18720/MCE.78.13.

13. P. Rohdin, A. Molin, B. Moshfegh. Build. and Env., 71, 176-185 (2014). DOI: 10.1016/j.buildenv.2013.09.017.

14. D.S. Tarasova, M.R. Petritchenko. Mag. of Civ. Eng., 4, 28-35 (2017).

15. D. Yang, J. Zhang. Build. and Env., 85, 29-39 (2015). DOI: 10.1016/j.buildenv.2014.11.019.

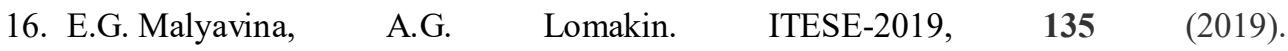
DOI: $10.1051 / \mathrm{e} 3$ sconf $/ 201913503018$

17. A.M. Shklover. Heat transfer at periodic thermal influences. (M-L.: Gosenergoizdat, 1961).

18. Yu.A. Tabunshikov, M.M. Brodach Mathematical modeling and optimization of thermal efficiency of buildings (2nd edition, revised and updated) (M: AVOK-PRESS, 2015)

19. E.G. Malyavina, Mat. Sc. For., 931, 910-913 (2018). DOI: 10.4028/www.scientific.net/MSF.931.910

20. E.G. Malyavina, A.A. Frolova, IOP Publishing. IOP Conf. Series: Mat. Sc. and Eng. 463022094 (2018) doi:10.1088/1757-899X/463/2/022094 